\title{
Programa de atenção a alunos precoces com comportamento de superdotação: identificação e proposta de enriquecimento musical
}

\author{
Fabiana Oliveira Koga* \\ Miguel Claudio Moriel Chacon**
}

\section{Resumo}

O presente artigo tem por objetivo abordar os processos de identificação e enriquecimento musicais que orientam os trabalhos desenvolvidos pela oficina de música do Programa de Atenção a Alunos Precoces com Comportamento de Superdotação (PAPCS). O PAPCS ocorre uma vez por semana, nos períodos matutino e vespertino, nas dependências da Faculdade de Filosofia e Ciências da Universidade Estadual Paulista (UNESP), Campus de Marília/SP. Participaram dessa coleta 17 alunos, com faixa etária compreendida entre cinco e 12 anos de idade. A identificação musical foi realizada por meio dos seguintes testes psicométricos: Primary Measures of Music Audition (PMMA) (GORDON, 1986a), Intermediate Measures of Music Audition (IMMA) (GORDON, 1986b). O trabalho de enriquecimento musical foi desenvolvido a partir do modelo de Renzulli (2004) e os resultados que serão contemplados aqui fizeram parte das oficinas musicais que ocorreram no PAPCS nos anos de 2014 e 2015. Os resultados obtidos permitiram concluir que, em meio aos 17 estudantes, 10 apresentaram acuidade auditiva elevada, ou seja, demonstraram um dos indicadores de precocidade e comportamento de superdotação.

Palavras-chave: Alunos precoces; Superdotação musical; Enriquecimento musical; Educação Especial.

\footnotetext{
* Doutoranda em Educação pela Universidade Estadual Paulista Júlio de Mesquita Filho, São Paulo, São Paulo, Brasil.

** Professor Doutor da Universidade Estadual Paulista Júlio de Mesquita Filho, São Paulo, São Paulo, Brasil.
} 


\section{Attention program for students with early behavior giffedness: identification and proposal for musical enrichment}

\section{Abstract}

This article aims to present the identification and musical enrichment processes that guides the work developed by the music workshop of the Attention Program For Students With Early Behavior Giftedness( PAPCS ). The PAPCS takes place once a week, in the morning and in the afternoon, in the premises of the Faculty of Philosophy and Science of São Paulo State University (UNESP), Campus Marília/ SP. Seventeen students participated in this collect, aged between 5 to 12 years old. The music identification was performed through the following psychometric tests: Primary Measures of Music Audition (PMMA) (GORDON, 1986a), Intermediate Measures of Music Audition (IMMA) (GORDON, 1986b). The work of musical enrichment was developed since Renzulli's model (2004) and the results that will be contemplated here were part of the music workshops that happened in the PAPCS during 2014 and 2015. The results allowed concluding that among those 17 students, 10 of them presented a high hearing acuity, so they show one of the indicators of early behavior and giftedness.

Keywords: Early students; Giftedness musical; Musical enrichment; Special Education.

\section{Introdução}

Dentre os programas que atuam na área da superdotação no Brasil está o Programa de Atenção a Alunos Precoces com Comportamento de Superdotação (PAPCS) da Faculdade de Filosofia e Ciências (FFC) da Universidade Estadual Paulista - UNESP, Campus de Marília/SP. Iniciado em 2011 sob a coordenação do professor Dr Miguel Cláudio Moriel Chacon, o PAPCS é um programa de extensão e pesquisa, que tem por objetivo identificar crianças precoces com comportamento de superdotação e oferecer atenção educacional especializada, tanto para as crianças identificadas, quanto para seus responsáveis legais, de acordo com a perspectiva teórica de Joseph $S$. Renzulli (CHACON; PEDRO; KOGA, 2014).

Inicialmente, as crianças chegam ao PAPCS por indicação de seus respectivos professores, que recebem capacitação sobre a temática em forma de curso de extensão oferecido pelo PAPCS, em parceria com a Secretária Municipal da Educação de Marília/SP, ou por demanda espontânea de suas respectivas famílias que as identificam por meio de alguns indicadores que lhes "saltam aos olhos" (WINNER,1998). Após as indicações iniciais, as crianças são encaminhadas para triagem no Centro de Educação e da Saúde (CEES) e no próprio PAPCS, onde são avaliadas por uma equipe multidisciplinar composta por profissionais das áreas de: psicologia, pedagogia, psicopedagogia, música e outros. Também é realizada uma entrevista com os pais, 
a fim de verificar informaçóes sobre o desenvolvimento da criança e a vida familiar. Em meio à avaliaçấo multimodal, destaca-se para este estudo a identificação musical (CHACON; PEDRO; KOGA, 2014).

Muitos são os aspectos que norteiam a identificação da precocidade e do comportamento de superdotação musical. Para Alencar e Fleith (2001) seriam: percepção (habilidade de discernir entre sons musicais); memória (habilidade de resgatar ritmos e sons ouvidos); reprodução (habilidade de recriar); gosto (habilidade individual de escolha por meio do senso de estética musical) e aptidáo artística (habilidade de expressão emocional e criativa realizada pelo próprio indivíduo).

Para Winner (1998), as crianças identificadas podem apresentar: memória musical, habilidade para improvisar e fascínio pela teoria musical (tipos de notaçóes e técnicas). Também, podem apresentar habilidade precisa para cantar, compor e executar um instrumento. A autora afirma que a superdotação musical pode se revelar cedo, antes dos seis anos de idade. Isto ocorre, porque a música é uma área de domínio altamente regida por regras e é formalmente estruturada, o que viabilizaria a manifestação desta área de domínio.

\begin{abstract}
A habilidade central da criança musicalmente superdotada envolve uma sensibilidade à estrutura da música - tonalidade, harmonia, ritmo. Esta sensibilidade permite que a criança lembre da música e a toque com facilidade através da voz ou de um instrumento. Esta sensibilidade à estrutura também permite que a criança transponha um tema para uma tonalidade diferente, improvise sobre um tema dado e invente melodias, tudo o que as crianças musicalmente superdotadas fazem com facilidade. As crianças musicalmente superdotadas demonstram grande sensibilidade à estrutura musical e isso nos espanta por ser raro. [...] A superdotação se revela muito cedo. De fato, a superdotação em música aparece antes do que a superdotação em qualquer outro domínio de habilidade. Muitos músicos e compositores famosos demonstraram superdotação musical táo cedo quanto aos dois anos e quase sempre antes dos seis. (WINNER, 1998, p. 76).
\end{abstract}

Para Kirnarskaya (2004), os indícios da superdotação para a música se manifestam pela habilidade musical, a qual, a autora define por mecanismos psicológicos cuja base se volta apenas para os aspectos perceptivos que compóem o ouvido expressivo, quais sejam: timbre, dinâmicas, articulação e acentuação, bases para a habilidade musical podendo culminar na superdotaçáo musical. Conforme teoriza a autora, a superdotaçáo musical se localiza na superdotaçáo produtivo-criativa, de acordo com a teoria de Renzulli (2003), sua característica concerne na capacidade do indivíduo de produzir e controlar níveis hierárquicos de elementos musicais, combinando-os e manipulando-os por meio de um ouvido expressivo, analítico, senso rítmico e ouvido arquitetônico culminando na habilidade produtivo-musical. 
Figura 1 - Percurso da Superdotação Musical

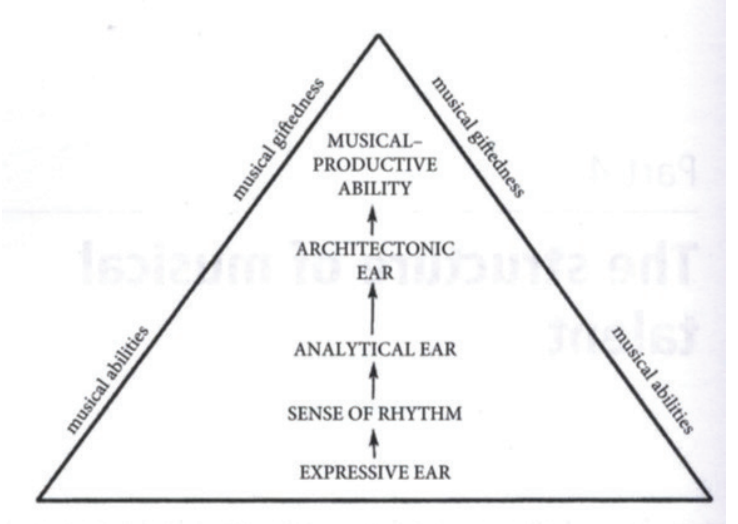

Fonte: Kirnarskaya (2004, p. 284).

Nos estudos de Kirnarskaya (2004) é preciso destacar a superdotação produtivo-criativa, teorizada por Renzulli (2004) e, considerada por ele, difícil de ser identificada, em virtude de suas especificidades, quando comparada a superdotação acadêmica. Para ambos os autores, este dificultador, muitas vezes, sugestiona necessidades como: adaptar instrumentos de avaliação e a criação ou a aquisição de outros. Indivíduos que são superdotados produtivos-criativos, como no caso da música, são, para Renzulli (2004), aqueles que realizaram feitos incomuns, e tendem a desempenhar melhor em áreas específicas e contextuais, em relação a um domínio, do que se destacarem mais abrangentemente. Para ele, o superdotado produtivo-criativo é capaz de desenvolver materiais e concepçóes originais e de pensar uma situação problema de maneira integrada e indutiva.

Por esta razão, em virtude das afirmaçóes de Kirnarskaya (2004) e Renzulli (2004), foi necessário buscar na literatura testes específicos da área da música que mensurasse sensivelmente aquelas crianças que dáo indícios de precocidade e superdotação para música. A partir desta busca, foi possível identificar os testes de acuidade auditava de Edwin Gordon: Primary Measures of Music Audition (PMMA) e Intermediate Measures of Music Audition (IMMA) (GORDON, 1986 a; b).

Validados em 1971, os testes de aptidão musical PMMA e IMMA foram desenvolvidos após longos anos de pesquisa experimental que definiram que os testes possuiriam 1114 padróes e possibilidades tonais e 486 rítmicas. O teste PMMA pode ser aplicado com crianças da Educação Infantil (a partir de quatro anos aproximadamente) até o ciclo I do Ensino Fundamental. Este teste funciona como uma primeira etapa de avaliação, ou seja, ele avalia o alcance máximo do estudante. O teste IMMA está indicado para utilização com crianças do Ciclo II do Ensino Fundamental permitindo que seu uso ocorra também no ciclo I do Ensino Fundamental, caso a criança já tenha sido submetida ao PMMA. O teste IMMA também avalia o alcance máximo do estudante. $\mathrm{O}$ autor realizou a criação de outros testes que permitem acompanhar 
longitudinalmente as crianças, quanto ao processo de musicalização, no decorrer de sua escolarização. Por esta razão, os testes abrangem desde Educação Infantil até o Ensino Superior (GORDON, 1997).

Embora a identificação seja importante, tornou-se imprescindível o acompanhamento longitudinal e especializado da criança identificada e de sua família. Afinal, segundo Gama (2006), a identificação sem o atendimento especializado não tem razão de ser. Por mais que a criança precoce com comportamento de superdotaçáo se destaque entre seus pares, sozinha não conseguirá se apropriar de aspectos técnicos, principalmente, quando se trata da área da música. Por esta razão, foi necessário ter um plano de enriquecimento musical, no PAPCS, para as crianças identificadas neste estudo. A seguir, uma proposta de enriquecimento que, atualmente, tem norteado os trabalhos da oficina de enriquecimento musical do PAPCS, após o processo de identificação dos estudantes iniciantes no programa.

Quadro 1 - Proposta de Enriquecimento Musical associada aos Tipos de Enriquecimento

\begin{tabular}{|c|c|}
\hline Educaçáo Básica & $\begin{array}{l}\text { Métodos e Enriquecimentos dos Tipos } \\
\text { I, II e III (RENZULLI; REIS, 2003) e IV } \\
\text { (FREITAS; PÉREZ, 2012) }\end{array}$ \\
\hline \multirow[t]{2}{*}{ Educação Infantil (RCNEI) } & Edwin E. Gordon (Tipo I, II) \\
\hline & Edgar Willems (Tipo I, II, III) \\
\hline \multirow{10}{*}{ Ensino Fundamental I e II (PCNS) } & Émile Jaques-Dalcroze (Tipo I, II, III) \\
\hline & Zoltán Kodály (Tipo I, II, III) \\
\hline & Carl Orff (Tipo I, II, III, IV) \\
\hline & Maurice Martenot (Tipo I, II, III) \\
\hline & Murray Schafer (Tipo I, II, III, IV) \\
\hline & Shinichi Suzuki (Tipo I, II, III, IV) \\
\hline & John Paynter (Tipo I, II, III, IV) \\
\hline & Jos Wuytack (Tipo II, III) \\
\hline & Violeta H. de Gainza (Tipo I, II, III, IV) \\
\hline & Gertrud Meyer-Denkmann (Tipo I, II) \\
\hline
\end{tabular}

Fonte: Elaborado pela autora

Ao observar o Quadro 1, é possível perceber os métodos ativos associados aos Tipos de Enriquecimento. Estes métodos são designados ativos por estarem baseados em uma perspectiva contemporânea do ensino musical, o qual a criança participa ativamente do processo de musicalização vivenciando, experimentando e fazendo a sua própria música, sem que seja introduzida diretamente em um instrumento musical, ou que seja exposta a aulas tradicionais de teoria musical (FONTERRADA, 2005). 
Os métodos ativos apresentados no Quadro 1, possuem perspectivas diferentes, o que permite associação aos Tipos de Enriquecimento, segundo Renzulli (2003), além de possibilitar que cada profissional os escolha de acordo com seu contexto de atuação.

Edwin Gordon desenvolveu um método de ensino musical com base na evolução da percepção rítmica e melódica começando este trabalho durante a primeira infância. Seu instituto, The Gordon Institute for Music Learning (GIML) ${ }^{1}$, promove cursos de formação para professores com o intuito de conscientizá-los com relação ao trabalho com os elementos musicais como tom, ritmo, dinâmica, timbre e outros. Nesta perspectiva, por exemplo, no trato com bebês, Gordon (2008) sugere que o professor balbucie sequências musicais improvisadas e aleatórias utilizando notas e ritmos executados com máxima perfeição e timbre bem definido formando uma harmonia. Assim, contribuirá para que o bebê, pouco a pouco, vá se apropriando da atmosfera sonora e, desta maneira, possa interagir e experimentar este ambiente harmônico.

De acordo com Ferreira (2011), o método Willems está posto para desenvolver a criança na perspectiva motriz, da imaginaçáo e da audição (sensorial, afetiva e mental). Segundo a autora "Willems considerava que o ritmo e movimento estấo presentes no ser humano em açóes tão naturais como andar ou respirar, no pulsar do coração, e em muitas das suas mais simples reações físicas e emocionais" (FERREIRA, 2011.p. 31, tradução nossa). ${ }^{2}$

Conforme os estudos de Mariani (2012), o método Dalcroze provém de um ensino voltado à consciência rítmica por meio de experiências corporais (sensaçóes físico-auditivas) e seu propósito se volta ao desenvolvimento de aspectos ligados à criatividade e expressão corporais em sintonia com a audição.

O método Kodály, segundo Houlahan e Tacka (2008), explora o solfejo melódico e rítmico por meio das cançóes infantis fazendo uso de intervalos, semitons e escalas, entre outros elementos. É preciso destacar que o método traz a representação musical adaptada para monossolfa, que consiste em uma sequência de gestos manuais também para realização do solfejo (SILVA, 2012). Este sistema, em virtude dos sinais, pode dinamizar o trabalho com surdos em aulas de Educação Musical.

O método Orff, conforme Bona (2012), Ferreira (2011) e Penna (2008), tem por objetivo desenvolver capacidades expressivas e perceptivas das crianças por meio do cantar, recitar, tocar, dançar e outros. Este método proporciona que a criança vivencie a música ludicamente, de maneira enriquecedora, por meio de quatro princípios elementares: música, movimento, linguagem e improvisação. Por envolver o uso de instrumentos como, por exemplo, o Orff-Instrumentarium, este método introduz a prática instrumental com as crianças.

De acordo com Fialho e Araldi (2012) o método Maternot se apoia no canto por imitação, canto consciente, leitura musical e teoria aplicada. Na perspectiva deste método estima-se por uma base sólida primando pela conexão com a prática. 
O método Schafer (1933), apresenta uma proposta de ensino não linear, baseada na assimilação de conceitos musicais como os sons, os ritmos, inclusive o que seria a própria música com seu ambiente sonoro. Schafer (1933) leva os estudantes à mais elevada reflexão, e procura descobrir, nesse processo, qual o potencial criativo de cada um para que se torne capaz de fazer sua própria música.

Para Ilari (2012), o método Suzuki está pautado em uma perspectiva na qual o potencial para música deverá ser impactado pelo meio ambiente favorável. Neste método a criança é trabalhada musicalmente considerando três dimensões: família, professor de música e estudante.

\begin{abstract}
Quando um jovem estudante meu, Koji Toyota tocou Humoresque, de Dvorák, no Japan Youth Hall, aos dois anos e cinco ou seis meses, a Asahi escreveu sobre ele nos dias seguintes como se ele fosse um gênio. Contudo, eu sei que aquele menino não demonstrou aquela habilidade de repente. O pai de Koji, também meu aluno, tocava violino todos os dias. Crescendo em tais realizaçóes, ele deu a Koji um pequeno violino e ministrou instruçôes a ele, diariamente; assim, ele foi capaz de tocar a peça. O resultado fez com que alguns o vissem como gênio baseado no fato de seu pai ter se esforçado para desenvolver a habilidade do filho (SUZUKI, 1996, p. 10, tradução nossa) $)^{3}$.
\end{abstract}

Diante de tais mençôes, a perspectiva do método Suzuki se volta para o treinamento sistemático, independentemente do grau de potencialidade que tenha o estudante. Este método enfoca a prática instrumental sendo bem conhecido pelos professores de instrumentos de cordas como violino, viola e violoncelo, além de primar pelo envolvimento com a tarefa associado a habilidade musical.

O método Paynter, para Ferreira (2011) e Mateiro (2012), valoriza a importância de formas criativas de aprendizagem partindo de três princípios: imaginaçáo, individualidade e exploração do material disponível. Para ele, a criança necessita de estímulos criativos para utilizar competências e até para adquiri-las. Dessa maneira, o criar torna-se algo importante e a exploraçáo de processos associados à criatividade podem indicar novas possibilidades.

O método Wuytack (PALHEIROS; BOURSCHEIDT, 2012), é composto por diversas atividades musicais que contemplam: ouvir ativamente, criar e interpretar por meio da improvisação, além do uso da voz e de instrumentos associados a tais processos. Com enfoque no trabalho coletivo, prevê que o aluno primeiro deve desenvolver a escutar para depois observar, e então, após reflexão, executar (diz-me, mostre-me e envolve-me).

Gainza (1988) propóe a observação do estudante de música com o intuito de conhecê-lo na perspectiva da música e assim poder investir em aspectos faltantes ou existentes enquanto potencialidade. Para a autora quando um indivíduo e/ou professor desconhece os elementos que compóem o desenvolvimento ou os aspectos faltosos na área da música, esses podem se tornar grandes obstáculos ao longo de todo o processo de aprendizado, mesmo que o estudante seja superdotado em música. 
De acordo com Souza (2012), o método de ensino musical de MeyerDenkmann apresenta uma concepção pedagógico-musical voltada para: ampliação das capacidades perceptiva e sensível; promoção da auto-realização no campo das relaçóes sociais; desenvolvimento das capacidades criativas e do pensamento produtivo, e preparação para a consciência crítica diante da oferta musical.

Por fim, é preciso explicitar que, tanto na oficina de enriquecimento musical, quanto nas demais oferecidas pelo PAPCS, as crianças são organizadas em três grupos (Educação Infantil e Ciclos do Ensino Fundamental I e II). A partir desta distribuição, inicia-se o processo de enriquecimento baseado no modelo de Renzulli e Reis (1985), que assim definem os Tipos de Enriquecimento: Tipo I - que se configura como experiências exploratórias gerais ou atividades de sondagem de interesses; Tipo II - consiste em atividades que exploram e acessam técnicas variadas e materiais instrucionais; Tipo III - configura-se por uma atenção mais individualizada, cujo objetivo trata-se de investigar problemas reais. Adicionalmente, o Tipo IV, de Freitas e Pérez (2012) que se caracteriza pela pesquisa de produtos reais individuais ou em pequenos grupos.

Diante de tudo que se mencionou, objetivou-se neste estudo identificar a precocidade e o comportamento de superdotação musical nos estudantes do PAPCS. Assim, mediante os resultados, trazer à tona uma gama de possibilidades de maximização do potencial musical das crianças identificadas na área da música, fazendo com que elas sejam atendidas na medida de sua necessidade, não ficando à margem do processo de musicalização, que se configura no processo de Educação Musical, e tão somente da Atenção Educacional Especializada.

\section{Método}

\section{Participantes}

Participaram da pesquisa 17 estudantes identificados no PAPCS como precoces com comportamento de superdotação. As idades dos participantes variaram entre cinco e 12 anos, sendo sete meninas e 10 meninos. Quanto ao grau de escolaridade, dois são da Educação Infantil, 11 são do Ensino Fundamental I e quatro são do Ensino Fundamental II.

\section{Procedimentos}

Inicialmente foi solicitada autorização para a coleta de dados no Centro de Estudos da Educaçáo e da Saúde (CEES) e, posteriormente ao Comitê de Ética da FFC/UNESP, Campus de Marília/SP, com aprovação (0649/2013), para a realizaçáo da pesquisa.

A avaliação musical foi realizada no PAPCS em 2013, o que aperfeiçoou as oficinas ocorridas em 2014 e 2015. Os instrumentos para a coleta de dados foram os testes PMMA e IMMA. Os mesmos foram ministrados individualmente e seguiram rigorosamente as indicaçóes de seus respectivos manuais. A aplicação de ambos atendeu à recomendação do teste para a duração de 20 minutos e ocorreu dentro de uma 
sala acústica de audiometria do CEES. Tanto para o PMMA quanto para o IMMA há gravações em CD para cada exercício, sendo primeiramente apresentados os sons de uma sequência de notas musicais para que o participante identificasse mudança nos tons. Posteriormente, foram apresentadas sequências de batidas rítmicas para que o participante discernisse se eram rigorosamente iguais ou diferentes. Para cada teste há uma folha de respostas específicas, ambas contêm oito sequências, cada qual com cinco exercícios a serem discernidos auditivamente e assinalados graficamente (Figuras 2 e 3). Inicialmente a criança é avaliada quanto ao tom (Figura 2) e, posteriormente, quanto ao ritmo (Figura 3). Para cada exercício são executadas seguidamente duas sequências e ao ouvi-las, o estudante deve circular as figuras iguais, para tons ou ritmos iguais ou as figuras diferentes, para tons ou ritmos diferentes.

Figura 2 - Uma das sequências da folha de resposta do Teste PMMA para discernimento Tonal
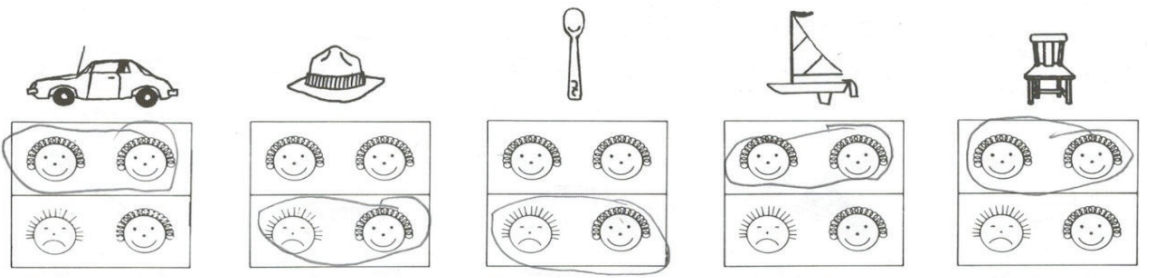

Fonte: Gordon (1986b, p. 37-38).

Figura 3 - Uma das sequências da folha de resposta do Teste IMMA para discernimento Rítmico

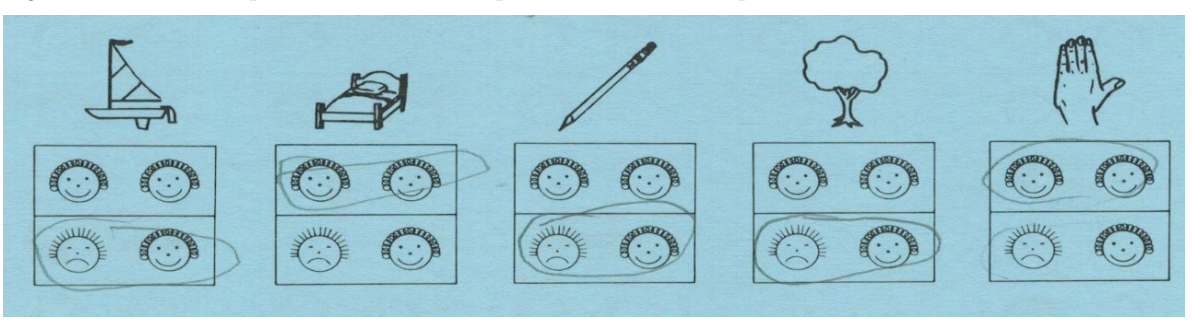

Fonte: Gordon (1986a, p. 43-44).

Feita a aplicação de cada teste, utiliza-se uma máscara corretora para cada uma das folhas de resposta dos respectivos testes. Cada teste possui um manual específico para converter os resultados brutos de cada estudante em escore (percentil), conforme a série e a idade cronológica da criança. De acordo com os manuais dos testes PMMA e IMMA a nota de corte estabelecida foi de 80 , ou seja, o estudante que se apresentasse acima desta estimativa poderia ser considerado com indicadores de precocidade e comportamento de superdotação.

Também compôs o processo de avaliação dos dados a análise da porcentagem de acertos de acordo com a média do grupo, além do uso do teste estatístico de Wilcoxon, de maneira a observar intragrupo, em virtude de haver a presença de duas variáveis tom e ritmo. 


\section{Resultados e discussão}

$\mathrm{Na}$ Tabela 1 é possível visualizar os resultados preliminares, os quais permitem identificar os estudantes que se destacaram musicalmente e os que ficaram na média ou inferior a ela. Primeiramente, o valor do escore bruto de cada criança foi correlacionado ao nível de escolaridade e idade, o que gerou o resultado Percentil que equivale ao nível de acuidade auditiva de cada um dos participantes, segundo o manual de cada teste. Também, foi possível contabilizar os mesmos escores brutos, o que permitiu atrelá-los ao número de itens (80) que compunham as folhas de resposta $\mathrm{T}$ (tom) e R (ritmo), geradores dos resultados de percentual de acertos de cada grupo. A seguir, na Tabela 1 serão apresentados esses dados preliminares.

Tabela 1 - Resultados preliminares dos testes PMMA e IMMA

\begin{tabular}{|c|c|c|c|c|c|c|}
\hline Gênero & Idade & $\begin{array}{c}\text { Ano } \\
\text { Escolar }\end{array}$ & Testes & $\begin{array}{c}\text { Escore } \\
\text { Bruto }\end{array}$ & $\begin{array}{c}\text { Rank } \\
\text { Percentil }\end{array}$ & $\begin{array}{c}\text { \% de } \\
\text { Acertos }\end{array}$ \\
\hline M1 & 5 & EI & PMMA & 49 & 59 & 61,25 \\
\hline F2 & 5 & EI & PMMA & 42 & 38 & 52,5 \\
\hline M3 & 6 & $1^{\text {o }}$ & PMMA & 36 & 7 & 45 \\
\hline M4 & 7 & $2^{\text {o }}$ & PMMA & 50 & 22 & 62,5 \\
\hline F5 & 7 & $2^{\text {o }}$ & PMMA & 59 & 46 & 73,75 \\
\hline M6 & 9 & $4^{\text {o }}$ & PMMA & 55 & 19 & 68,75 \\
\hline F7 & 9 & $4^{\text {o }}$ & PMMA & 77 & 96 & 96,25 \\
\hline F8 & 9 & $4^{\text {o }}$ & PMMA & 62 & 40 & 77,5 \\
\hline M9 & 9 & $4^{\text {o }}$ & PMMA & 64 & 46 & 80 \\
\hline F10 & 10 & $5^{\circ}$ & IMMA & 59 & 1 & 73,75 \\
\hline M11 & 10 & $5^{\circ}$ & IMMA & 71 & 60 & 88,75 \\
\hline M12 & 10 & $5^{\circ}$ & IMMA & 65 & 15 & 81,25 \\
\hline M13 & 10 & $5^{\circ}$ & IMMA & 65 & 15 & 81,25 \\
\hline F14 & 12 & $7^{\circ}$ & IMMA & 73 & 75 & 91,25 \\
\hline M15 & 12 & $7^{\circ}$ & IMMA & 48 & 0 & 60 \\
\hline M16 & 12 & $7^{\circ}$ & IMMA & 68 & 30 & 85 \\
\hline F17 & 12 & $7^{\circ}$ & IMMA & 48 & 0 & 60 \\
\hline
\end{tabular}

Fonte: Elaborado pelo autor

Legenda: M: masculino; F: Feminino; EI: Educação Infantil.

Conforme parâmetros estatísticos dos testes, o estudante que apresentou escore abaixo de 20 foi considerado inferior, entre 20 e 79 foi considerado na média e acima de 80 foi considerado superior, ou seja, precoce com comportamento de superdotação musical. O Percentil gerado a partir do resultado de escore bruto permitiu 
estabelecer relação prévia entre o esperado e o encontrado, ou seja, observar a média do grupo em termos de rendimento. Diante desta relação observa-se que no gráfico 1, é possível identificar apenas uma estudante (F7) que, independente do escore bruto, atingiu Percentil superior a 80 (96). Há que se observar que F7 não estuda formalmente a música e foi encaminhada para o PAPCS em virtude de seu destaque acadêmico e não musical.

Gráfico 1 - Escore bruto e percentil dos testes PMMA e IMMA

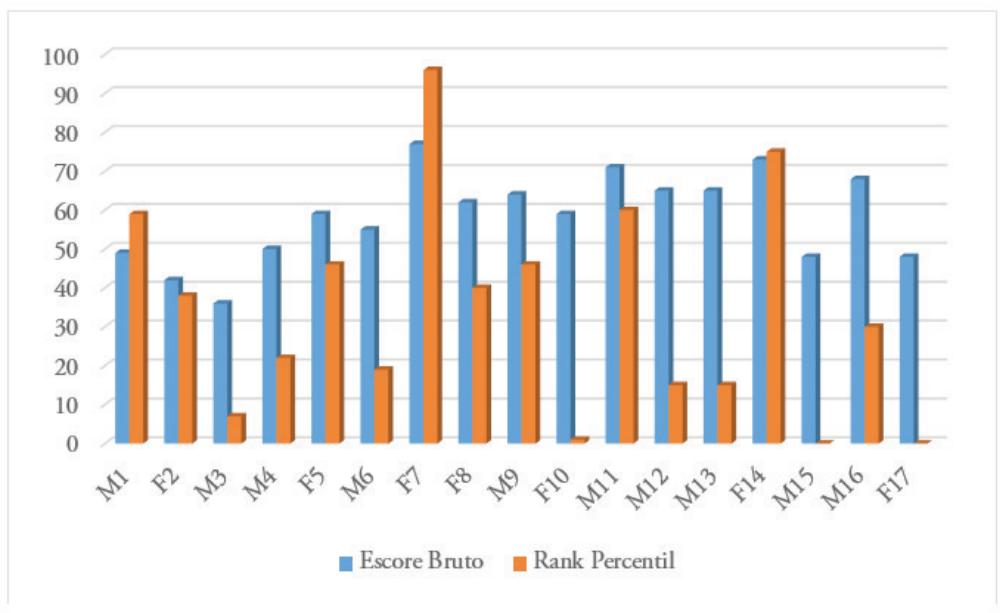

Fonte: Elaborado pelo autor.

Após revelar os resultados entre o escore bruto e o Percentil dos testes, é possível observar no Gráfico 2 os estudantes que mais se destacaram conforme o nível escolar (Educação Infantil, Ensino Fundamental I e II), a fim de uma observação mais geral. Por haver diferenças na média para cada ano escolar no momento da conversão dos resultados brutos em escore, o Gráfico 2 expressa o agrupamento dos estudantes segundo o nível de escolaridade. Desta maneira, têm-se os resultados diferenciados, conforme mostrou o gráfico 1, sendo dois na Educaçáo Infantil, e os demais no Ensino Fundamental. Destes, um se encontrava no $1^{\circ}$ ano, dois no $2^{\circ}$ ano, quatro no $4^{\circ}$ ano, quatro no $5^{\circ}$ ano e quatro no $7^{\circ}$ ano. 
Gráfico 2 - Percentual de acertos com base na média prevista pelo teste PMMA

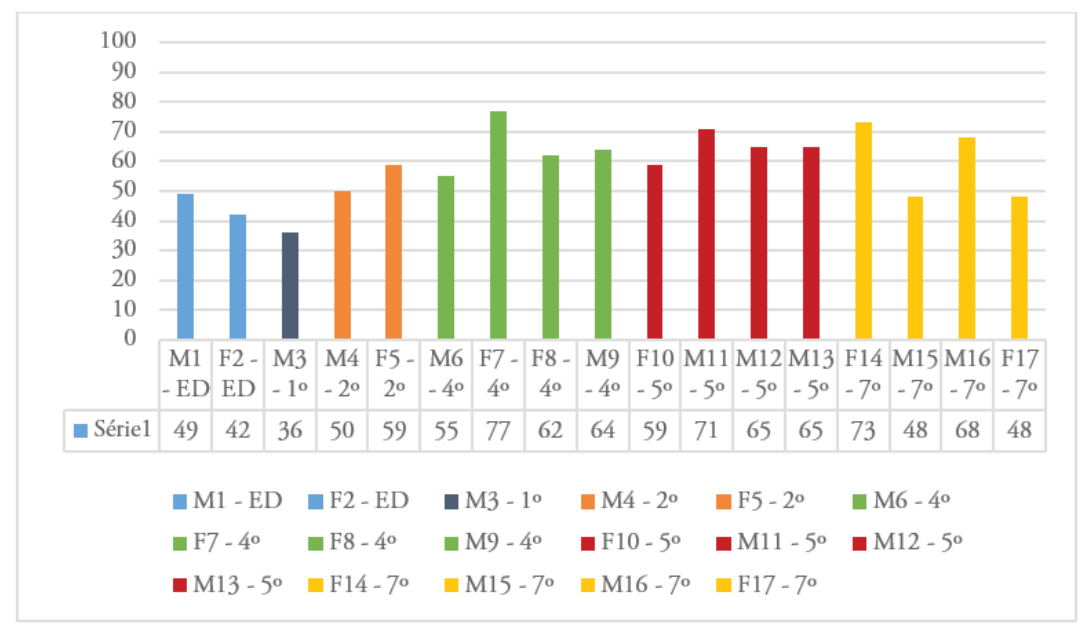

Fonte: Elaborada pelo autor.

A seguir, ao observar o gráfico 3, é possível identificar 10 participantes, quando considerado a média intragrupo. O máximo valor pertence à participante F7 $(96,3)$, em segundo lugar F14 $(91,3)$, em terceiro M11 $(88,8)$ e, posteriormente, os demais participantes M12 e M13 (81,3), M9 (80), F8 $(77,5)$ e F10 e F5 $(73,8)$.

Gráfico 3 - Percentual de acerto do grupo nos testes PMMA e IMMA

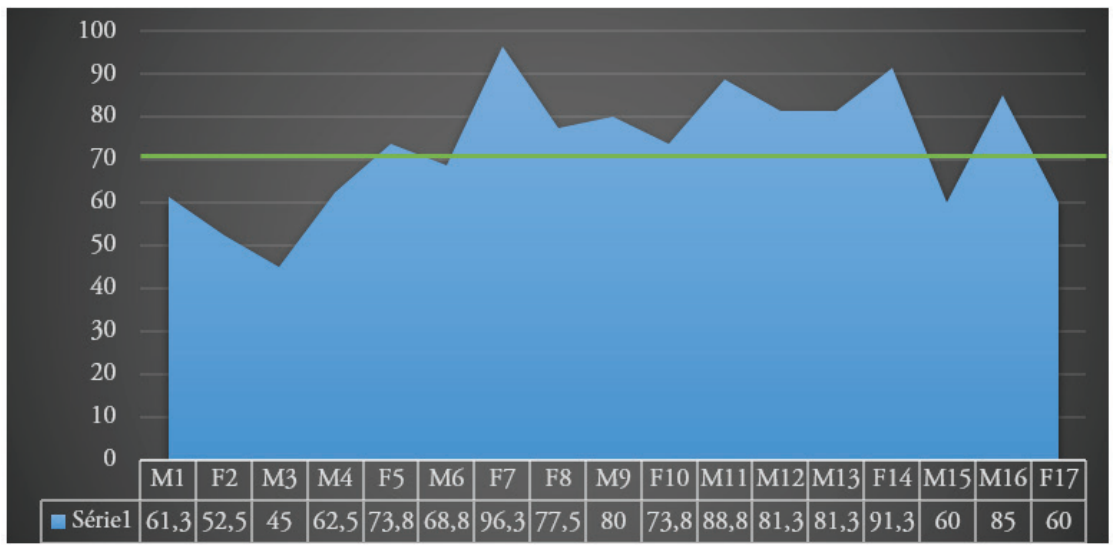

Fonte: Elaborado pelo autor.

Legenda: média do grupo foi de 72,86. 
Ao observar todos os resultados, inclusive o do gráfico 3, foi possível identificar que os 10 participantes que conseguiram discernir os tons e ritmos adequadamente, permitindo, assim, inferir que havia índices de precocidade e comportamento de superdotação musical em meio aos 17 participantes totais.

Diante disso, é possível trazer à tona as afirmações de Gordon (1997) que relata que a capacidade de discernir tons e ritmos, advém da capacidade de classificação formal de um objeto, uma atividade mental de análise, que inicia a prática do pensamento abstrato, imprescindível para exercer diferentes atividades, dentre elas, a prática do discernimento tonal e rítmico. Diante do número de participantes que se destacaram, conforme mostra o gráfico 3, é possível inferir que estes se destacaram porque conseguiram a abstração perceptiva necessária para a realização dos testes. $\mathrm{O}$ que significa que abstraíram o todo (frases melódicas) das partes (tons e as batidas rítmicas isoladas).

Em consonância, Kirnarskaya (2004) afirma que quando a diferença das medidas entre tom e ritmo não são discrepantes, estas estariam demonstrando que há a presença do ouvido analítico, ou seja, seria esta a fronteira para a superdotação musical. Para ela, o ouvido analítico é importante porque o sujeito que o tem, é capaz de ouvir a frase melódica como um todo e ao mesmo tempo fraciona-la percebendo as partes, conforme Gordon (1997) explicitou anteriormente. Para ela, o ouvido analítico é flexível permitindo que o sujeito o adeque ao contexto do evento musical.

Para observar se tais afirmaçóes se confirmam nesta amostra, fez-se necessário analisar cada uma das variáveis (tom e ritmo) presentes neste estudo, por meio do teste Wilcoxon, de maneira a observar, intragrupo, se houve, em alguma, predominância de alguma variável, o que confirmaria a presença do ouvido analítico ou náo. A proximidade das medidas entre os valores de tom e ritmo, permite inferir a manifestação do ouvido analítico, assim permitindo assegura indícios de precocidade e comportamento de superdotação musical nos respectivos participantes deste estudo.

Tabela 2 - Desempenho tonal e rítmico de G1 no PMMA e IMMA

\begin{tabular}{|c|c|c|c|}
\hline Testes & $\begin{array}{c}\text { Variaçáo (Min- } \\
\text { Máx) }\end{array}$ & Mediana & Dispersáo (Q1-Q2) \\
\hline PMMA TOM & $17-40$ & 26 & $24-32$ \\
\hline PMMA RITMO & $19-37$ & 28 & $24-30$ \\
\hline IMMA TOM & $23-39$ & 32 & $28,5-35,75$ \\
\hline IMMA RITMO & $24-35$ & 33 & $26,5-33,25$ \\
\hline Total & $17-40$ & 29,75 & $25,75-32,75$ \\
\hline
\end{tabular}

Fonte: Elaborado pela autora

Inicialmente, observou-se os resultados dos participantes que realizaram o teste PMMA, e foi possível verificar diferença na variação que é maior no aspecto tonal, porém na mediana o maior valor está no aspecto rítmico, enquanto a dispersão está 
maior no aspecto tonal. Quando submetido os resultados do teste PMMA, ao teste de Wilcoxon, se obteve $\mathrm{p}=0,2129$, considerado estatisticamente não significante. $\mathrm{O}$ que demonstra que estatisticamente há uma aproximação quase equilibrada entre tom e ritmo, embora haja diferença nos valores das medidas, o que se configura na presença do ouvido analítico.

Ao avaliar o desempenho tonal e rítmico dos resultados no teste IMMA, por meio do teste Wilcoxon, obteve-se $\mathrm{p}=0,2344$, considerado estatisticamente náo significante. Por meio da distribuiçáo de medidas, observa-se a proximidade dos valores, demonstrando assim a presença do ouvido analítico, também.

No entanto é preciso destacar que embora haja uma pequena vantagem no teste IMMA para a variável ritmo, o teste de Wilcoxon mostra que esta diferença não é significante em ambos os testes, por esta razão, é possível afirmar a manifestação do ouvido analítico, ou seja, que há indícios de precocidade e comportamento de superdotaçáo musical, principalmente quando é considerado o escore de F7 que se destacou superior no teste PMMA.

À vista dos resultados é possível observar que dos 17 participantes, 10 são bastante favoráveis ao enriquecimento musical em virtude de apresentarem acuidade auditiva acurada. No entanto, a proposta do PAPCS é trabalhar o Modelo de Enriquecimento de Renzulli (2004), ou seja, o enriquecimento voltado para todas as crianças. Diante disso, a proposta de enriquecimento realizada neste trabalho endossa esta perspectiva disseminada por Renzulli (2004) e, por esta razão, buscou-se na Educação Musical métodos que estivessem em consonância com os ideais da teoria de Renzulli $(2003$; 2004) capazes de embasar a criação das atividades a serem realizadas, conforme a necessidade que cada criança apresentava. Estes métodos contribuíram para traçar um plano de trabalho longitudinal, iniciado em 2014, possibilitando atender a cada uma das fases escolares. Estes métodos foram escalonados ${ }^{4}$ conforme as etapas da Educação Básica, além de cuidar para que eles pudessem atender a cada um dos Tipos de Enriquecimento.

A teoria da aprendizagem musical de Gordon (2014) foi explorada com os estudantes que se encontravam no período da Educação Infantil. Trabalhou-se o método Gordon para atender os Enriquecimentos dos Tipos I e II. Isto, porque, o método está voltado para a exploração sonoro-musical geral e por apresentar a técnica e os elementos da linguagem musical, ludicamente compartilhados com a criança.

O método Willems (PAREJO, 2012), também pode ser explorado com as crianças do período da Educação Infantil, porque atendeu aos Enriquecimentos do Tipo I, II e III. O Tipo I na medida, ao propor a exploração das cançôes populares abordando amplamente as escalas, os intervalos, os ritmos, letras, velocidades, rimas, acordes, movimentos corporais e outros; o Tipo II, por propor o início da codificação simbólica dos elementos musicais; do Tipo III, quando propôs a passagem do concreto para o abstrato, por meio do desenvolvimento das faculdades criativas mediante improvisação. Embora seja um método destinado para a Educação Infantil, ele pode se estender até o ciclo I do Ensino Fundamental. Seu limite de idade está posto dos três aos sete anos. 
O método Dalcroze (MARIANI, 2012) foi direcionado para o trabalho com as crianças que se encontram no período do Ensino Fundamental e atendeu aos enriquecimentos dos Tipos I e II. Aquele, em virtude do trabalho se concentrar em atividades exploratórias na área rítmica de maneira abrangente, atingindo todas as possibilidades rítmicas presentes no universo musical do contexto; este, em virtude de a abordagem rítmica atender aos aspectos teóricos que foram apresentados a criança, primeiro ludicamente e, posteriormente, foi contextualizado mediante aspectos técnicos e teóricos.

O método Kodály (HOULAHAN; TACKA, 2008; SILVA, 2012), também se destinou para crianças que estavam no Ensino Fundamental e atendeu aos Enriquecimentos dos Tipos I, II e III. O Tipo I, quanto foi proposto a exploração sonora, por meio da solmização (uso de sílabas para solfejar alturas); o Tipo II, ao introduzir os elementos técnicos e teóricos, sempre lúdicos, que permitiram chegar ao Tipo III, no qual o indivíduo será capaz de realizar seu próprio solfejo e até mesmo, com ou sem partitura, construir seu próprio solfejo e improvisar outras possibilidades.

O método Orff (BONA, 2012) não foi explorado ainda no PAPCS, no entanto, ele atende a todos os Tipos de Enriquecimentos. O Tipo I ao propor a exploração geral das cançóes infantis por meio do contato com variados padrôes rítmicos, melódicos, movimentos corporais, rimas e outros, o Tipo II por propor ao estudante que se aproprie da linguagem musical, os Tipos III e IV pela criação improvisada do próprio estudante, por meio da apropriação da técnica, que conduz ao desenvolvimento da performance.

Fialho e Araldi (2012) descrevem o método Maternot, que também não foi explorado no PAPCS, mas que pode ser utilizado nos Enriquecimentos dos Tipos I, II e III. No Tipo I, por meio da proposta de exploraçáo rítmica e do canto espontâneo (responsável pelo desenvolvimento da memória musical e ouvido interno), por meio de cançôes do repertório cultural, no qual a criança está inserida; no Tipo II, ao desenvolver o canto consciente por meio do solfejo e leitura formal da música, por meio do contato com os símbolos que representam as duraçóes e alturas; no Tipo III, ao estudar a teoria aplicada e a educação sensorial sistematizada.

O método Suzuki $(1983 ; 1996)$, atende aos quatro Tipos de Enriquecimentos. Do Tipo I, ao propor que a exploração musical antes da Educação Musical formal, muitas vezes, pela própria família ou pelo meio em que vive, o Tipo II, a partir do momento em que a criança é encaminha para a Educaçáo Musical formal para que se aproprie da linguagem musical, estabelecendo relação com aquilo que traz consigo enquanto aprendizado de música extra escola, do Tipo III, no momento em que a criança passa a estudar especificamente um dado instrumento, sendo apresentada à técnica; e do Tipo IV, no momento em que a criança se apropria da técnica e demonstra habilidade acima da média, altos níveis de criatividade e envolvimento com a tarefa, conforme postula a teoria dos anéis de Renzulli e Reis (1985). No momento no PAPCS há apenas um dos estudantes que está sendo exposto ao método Suzuki em virtude do Enriquecimento do Tipo III. 
Murray Schafer (SCHAFER, 2011) atende a todos os Tipos de Enriquecimento. De acordo com a método do autor, se torna possível a relação com o Tipo I quando propóe que se faça a exploraçáo ampla dos recursos sonoros disponíveis no meio cultural. O Tipo II é atendido no momento em que o autor propôe pesquisar verticalmente os elementos sonoros decorrentes da exploraçáo e classificá-los utilizando os elementos formais da música. O Tipo III é atendido, também, no momento que o autor propóe que o estudante, utilizando os sons pesquisados e classificados, criando sua própria música. O Tipo IV é atendido, no método Schafer, no momento em que o estudante se torna compositor. No PAPCS pouco a pouco está se introduzindo a perspectiva do método Schafer, principalmente com os estudantes que estão Ensino Fundamental II.

O Método Paynter (MATEIRO, 2012) atende a todos os Tipos de Enriquecimento. No Tipo I, propóe que os estudantes sejam expostos a todo tipo de sons e ritmos, além de outros elementos musicais de maneira diversificada e abrangente; no Tipo II o autor propóe a experimentação e aquisição de técnicas para o desenvolvimento da criação e manipulação dos elementos da linguagem musical; nos Tipos III e IV o estudante está compondo criativamente sua própria música por meio de elementos da linguagem musical que aprendeu a dominar. O autor incentiva a produçáo da música contemporânea a partir de elementos demiurgos. Este método ainda não foi explorado pela oficina de música do PAPCS.

Não atendeu às atividades do Tipo I o método Wuytack (PALHEIROS; BOURSCHEIDT, 2012), porém pode ser usado para o Enriquecimento do Tipo II, em virtude da apresentação da técnica e dos elementos da linguagem musical de maneira mais específica que exploratória. O Tipo III é atendido no momento que sua metodologia propóe a aplicação das técnicas aprendidas por meio da performance, e o Tipo IV é contemplado no momento que propóe a improvisação que corresponde ao fazer sozinho, mediante criação. Este método ainda não foi explorado pelo PAPCS em virtude dos outros métodos, anteriormente citados, terem atendido mais as necessidades de desenvolvimento dos estudantes identificados.

Violeta H. de Gainza (1988) atendeu ao Enriquecimento do Tipo I por meio da proposta de exploraçáo dos elementos musicais a fim de trabalhar o desenvolvimento da musicalidade. O Tipo II consiste na capacidade de dominar os elementos musicais por meio do desenvolvimento técnico e teórico. O Tipo III está ligado a aplicação dos elementos técnicos e o Tipo IV ao domínio pleno e profissional dos elementos musicais aplicados mediante performance. Este método tem sido a base principal para o desenvolvimento das atividades mais especificas com os estudantes que se encontram no Tipo III e IV de Enriquecimento.

Por fim, o método Denkmann (SOUZA, 2012) no máximo alcança até o Enriquecimento do Tipo II, em virtude de sua proposta pedagógica musical propiciar e sugerir atividades com os elementos musicais de maneira exploratória, com base na apresentação e experimentação. Este método é explorado com os estudantes que estão no período da Educação Infantil. 
Ao observar todos os métodos ativos da área da música, arroladas, percebeu-se que, de maneira geral, vários deles atenderam aos Tipos de Enriquecimento conforme a teoria de Renzulli e Reis (1985) e de Freitas e Pérez (2012). No entanto, há peculiaridades entre eles, os quais revelam que, conforme a proposta e o objetivo teórico de cada um, atenderá a todos os Tipos de Enriquecimento ou apenas a alguns.

É ressaltar que, ao elencar os métodos ativos e as atividades, como as desenvolvidas na oficina de música, pode-se observar o uso de mais de um método ativo, isso porque, a oficina de música é planejada sempre buscando desafiar os estudantes e apresentar referenciais conceituais novos e diferentes a fim de náo tornar os conteúdos respetivos. No entanto, isso não é uma regra, é possível utilizar um único método ativo para cada período da Educação Básica, sempre considerando a faixa etária estabelecida pelo método. O importante é que os trabalhos de Enriquecimento sejam pautados em suplementar os conteúdos que a escola e a família não conseguem contemplar no dia a dia da criança.

Alguns métodos se aproximam, em termos de objetivo conceitual e pedagógico, por isso, ainda náo foram explorados pelo PAPCS, como se mencionou anteriormente. Por esta razão, profissionais da Educação Musical e/ou escolas, que utilizarem os métodos ativos, deverão observar qual destes métodos, ou quais deles, se adequariam mais aos objetivos de trabalho, com os seus estudantes, e recursos disponíveis no seu entorno.

Quanto aos Tipos de enriquecimento, não há uma fórmula pronta. Isto dependerá da resposta ao enriquecimento, mensurada pelo processo de observação e avaliação longitudinais, fornecida a cada dia de trabalho, pelos estudantes individualmente, o que dará ao professor elementos para decidir se passa ou não para o Tipo seguinte de Enriquecimento.

Cada professor encontrará uma resposta diferente ao enriquecimento musical, que irá variar de estudante para estudante. É preciso salientar que pode haver estudantes que comecem em Tipos avançados de Enriquecimento como os Tipos II, III e até IV, em virtude da especificidade de sua área de domínio, por exemplo, como a composição, o canto e a performance de maneira geral.

Estas são algumas perspectivas que permitem atuar no processo de Enriquecimento musical conforme o perfil e contexto no qual se trabalha. Outros métodos ativos vigoram no cenário da Educação Musical, cabe aos educadores interessados, identificar qual se adequa mais aos objetivos da instituição na qual se atua. Estas perspectivas têm sido de grande valia para o desenvolvimento dos trabalhos musicais no PAPCS, mas ressalta-se que embora se tenha um planejamento sempre será preciso inovar, afinal, cada criança é única e precisa ser vista na medida de sua diferença e necessidade.

\section{Considerações finais}

A avaliação tem um papel importante no processo de identificação da criança com indicadores de precocidade e comportamento de superdotaçáo, principalmente 
em música. No entanto, este processo não pode se fragmentar apenas a identificação. $\mathrm{Na}$ realidade ele precisa ser continuo contribuindo para que a criança desenvolva seu potencial ao máximo.

Nesta perspectiva foi possível observar que de 17 crianças 10 apresentaram-se favoráveis ao enriquecimento musical. O que demonstra a importância da identificação, a fim de conhecer os indivíduos, para, assim, propor práticas precisas de intervenção e não avaliar por avaliar.

A identificação de crianças e jovens superdotados deve ser feita como componente ou etapa de um sistema de planejamento de programa educacional especial. Por conseguinte, a identificação tem que estar diretamente ligada aos objetivos de tal programa. Assim, o programa que visa dar uma educação musical de excelência às crianças e jovens superdotados deve ter, como instrumento de identificação, avaliaçôes do potencial musical dos candidatos, para que os mesmos possam vir a usufruir de tal programa (GAMA, 2006, p. 58).

No trabalho do PAPCS, a oficina de enriquecimento musical, bem como as demais oficinas, representam o acesso e a continuidade de um processo longitudinal de avaliaçáo permitindo, aos pesquisadores ali alocados, possibilidades de investigação sobre quem é esta criança ou jovem precoce com comportamento de superdotação que está no processo de identificação. De modo geral, as oficinas de enriquecimento do PAPCS, inclusive a oficina de enriquecimento musical, tem a preocupação de contribuir para que a criança identificada tenha condiçóes melhores de desenvolvimento do seu potencial e principalmente, qualidade de vida. Assim, através do Enriquecimento segundo Renzulli (2004), o PAPCS viabiliza a todos os seus estudantes triados, contato com conteúdos diversificados e o aprimoramento colaborativo, por meio dos especialistas que ali estấo voluntariamente e/ou mediante estágio.

No entanto, todos os profissionais do PAPCS têm consciência que suas açóes ainda são limitadas porque há muito mais crianças com precocidade e comportamento de superdotação ainda não identificadas e atendidas no ambiente escolar. Porém, embora sua abrangência seja pequena, tem sido de grande impacto e valia para alguns estudantes que se encontram com baixo recurso econômico e dificuldades de acesso aos conteúdos e áreas de seu interesse.

Assim como o PAPCS, é preciso salientar que há outros programas como o PIT $^{5}, \mathrm{Naahs}^{6}$ e o $\mathrm{CEDET}^{7}$, por exemplo, também contribuem para o desenvolvimento das potencialidades de crianças identificadas como precoce com comportamento de superdotação, inclusive em música. No entanto, existem outras iniciativas subsidiadas pelo Estado e Municípios como o projeto GURI ${ }^{8}$ que proporciona o estudo musical em específico, o Conservatório Dramático Carlos de Campos ${ }^{9}$, da cidade de Tatuí/ SP, e Escola Municipal de Música de Ourinhos ${ }^{10}$ e outros. Embora existam estas possibilidades de atenção as crianças identificadas como precoces com comportamento de superdotação musical, estas ainda são iniciativas insipientes e não conseguem atender a todas as crianças identificadas. Por esta razão, caso a escola trabalhasse na perspectiva do Modelo de Enriquecimento de Renzulli (2004) associada a Lei No 11.769, muito mais crianças poderiam estar sendo atendidas. 
Como tudo no Brasil exige força de lei, espera-se que com a Educação Musical, exigida como parte integrada do currículo escolar, e a legislação que garante forçadamente a atenção aos estudantes superdotados possam viabilizar que todas as crianças tenham um futuro melhor, que as valorizem mediante seus diferenciais e, sobretudo permitam que suas potencialidades se desenvolvam plenamente, e ao máximo, principalmente na área da música.

\section{Referências}

ALENCAR, E. M. L. S.; FLEITH, D. S. Superdotados: determinantes, educação e ajustamento. 2. ed. São Paulo: EPU, 2001.

BONA, M. Carl Orff: um compositor em cena. In: MATEIRO, T.; ILARI, B. (Org.). Pedagogias em educaçáo musical. Curitiba: Intersaberes, 2012. p. 125-156.

CHACON, M. C. M.; PEDRO, K. M.; KOGA, F. O. Programa de Atençấo ao aluno Precoce com Comportamentos de Altas Habilidades/Superdotaçáo (PAPAHS). La Nouvelle Revue de l'Adaptation et de la Scolarisation, Paris, v. 65, p. 13-29, 2014.

FERREIRA, C. H. L. J. A criatividade na aprendizagem da formaçáo musical. 2011. 64 f. Dissertaçăo (Mestrado em Música) - Departamento de Comunicaçáo e Artes, Universidade de Aveiro, Aveiro, 2011. Disponível em: <https://ria.ua.pt/bitstream/10773/6633/1/5132.pdf>. Acesso em: 16 jun. 2014.

FIALHO, V. M.; ARALDI, J. Maurice Martenot: educando com e para a música. In: MATEIRO, T.; ILARI, B. (Org.). Pedagogias em educaçáo musical. Curitiba: Intersaberes, 2012. p. 157-184.

FONTERRADA, M. T. O. Tramas e fios: um ensaio sobre música e educaçáo. São Paulo: Unesp, 2005.

FREITAS, S. N.; PEREZ, S. G. P. B. Altas habilidades/superdotaçáo: atendimento especializado. 2. ed. Marilia: ABPEE, 2012.

GAMA, M. C. S. S. Educaçáo de superdotados: teoria e prática. São Paulo: EPU, 2006.

GAINZA, V. H. Estudos de psicopedagogia musical. Trad. de Beatriz A. Cannabrava. 3. ed. São Paulo: Summus, 1988.

GORDON, E. Intermediate Measures of Music Audition. Chicago: GIA Publication, 1986a.

GORDON. E. Primary Measures of Music Audition. Chicago: GIA Publication, 1986b.

GORDON, E. E. Music, the brain, and music learning: mental representation and changing cortical activation patterns through learning. Chicago: GIA Publication, 1997.

GORDON, E. The Gordon Institute for Music Learning. Chicago: GIA Publication, 2008. Disponível em: <http://www.giml.org>. Acesso em: 19 jun. 2014.

HOULAHAN, M.; TACKA, P. Kodály today: a cognitive approach to elementary music education. New York: Oxford, 2008.

ILARI, B. Shinichi Suzuki: a educação do talento. In: MATEIRO, T.; ILARI, B. (Org.). Pedagogias em educação musical. Curitiba: Intersaberes, 2012. p. 185-218.

KIRNARSKAYA, D. The natural musician: on abilities, giftedness and talent. Trad. do russo por Mark $\mathrm{H}$ Teeter. New York: Oxford, 2004.

MARIANI, S. É. Jaques-Dalcroze: a música e o movimento. In: MATEIRO, T.; ILARI, B. (Org.). Pedagogias em educaçáo musical. Curitiba: Intersaberes, 2012. p. 25 - 54.

MATEIRO, T. John Paynter: a música criativa nas escolas. In: MATEIRO, T.; ILARI, B. (Org.). Pedagogias em educaçáo musical. Curitiba: Intersaberes, 2012. p. 243 - 267.

PALHEIROS, G. B.; BOURSCHEIDT, L. Jos Wuytack: a pedagogia musical ativa. In: MATEIRO, T.; ILARI, B. (Org.). Pedagogias em educaçáo musical. Curitiba: Intersaberes, 2012. p. 305 - 326.

PAREJO, E. Edgar Willems: um pioneiro da educaçáo musical. In: MATEIRO, T.; ILARI, B. (Org.). Pedagogias em educação musical. Curitiba: Intersaberes, 2012. p. 89-123.

PENNA, M. Música (s): e seu ensino. Porto Alegre: Sulina, 2008. 
RENZULLI, J. S. O que é essa coisa chamada superdotaçáo e como a desenvolvemos? Uma retrospectiva de vinte e cinco anos. Educação, Porto Alegre, v. 52, n. 1. p. 75 - 131, jan./abr. 2004.

RENZULLI, J. S.; REIS, S. M. The schoolwide enrichment model: a comprehensive plan for education excellence. Connecticut: Creative Learning Press, 1985.

RENZULLI, J. S.; REIS, S. M. The schoolwide enrichment model: a comprehensive plan for education excellence. In: COLANGELO, N.; DAVIS, G. A. (Org). Handbook of gifted education. Boston: Pearson Education, 2003. p. 184-203.

SCHAFER, R. M. O ouvido pensante. 2 ed. São Paulo: UNESP, 2011.

SILVA, W. M. Zoltán Kodály: alfabetização e habilidades musicais. In: MATEIRO, T.; ILARI, B. (Org.). Pedagogias em educaçáo musical. Curitiba: Intersaberes, 2012. p. 55 - 87.

SOUZA, J. Gertrud Meyer-Denkmann: uma educadora musical na Alemanha pós-Orff. In: MATEIRO, T.; ILARI, B. (Org.). Pedagogias em educação musical. Curitiba: Intersaberes, 2012. p. 219 - 241.

SUZUKI, S. Educação é amor: um novo método de educação. 2 ed. Santa Maria: Imprensa Universitária, 1983. [1969] versão inglesa do original japonês.

Young children's talent education $\&$ its methods. Trad. de Kyoko Selden. Miami: Summy-Birchard, 1996. p. 10

WINNER, E. Crianças superdotadas: mitos e realidades. Trad. Sandra Costa. Porto Alegre: Artmed, 1998.

\section{Notas}

${ }^{1}$ The Gordon Institute Music Learning - http://giml.org/publications/.

2 [...] "Dans l'éducation musicale il est utile, voire indispensable, que le rythme soit réalisé physiquement. Il doit être vécu physiologiquement, soit en réalité, soit par l'imagination motrice resultant d'expériences physiologiques" (FERREIRA, 2011, p. 31).

${ }^{3}$ When one of my young students, Koji Toyota, performed Dvorak's Humoresque at the Japan Youth Hall at two years and five or six months, the Asahi wrote about him in the following day's paper if he were a genius. However, I know that this boy did not suddenly demonstrate that ability. Koji's father, also my student, played the violin every day. Growing in such an environment, Koji was given a small violin, by his father and received daily instruction from him; thus he was able to play the piece. The result, which caused some to see genius in him stemmed in fact from his father's effort to develop the child's ability (SUZUKI, 1996, p. 10).

${ }^{4}$ Quadro 1.

5 PIT - Programa de Incentivo ao Talento < http://cascavel.ufsm.br/revistas/ojs-2.2.2/index.php/educacaoespecial/ article/view/4181>

${ }^{6}$ Naahs - Núcleo de atividades de altas habilidades/superdotação <(http://www.ldanaahs.seed.pr.gov.br/modules/ noticias/)>.

${ }^{7}$ CEDET - Centro para o desenvolvimento do potencial e do talento - Responsável: Prof.a Dra. Zenita Guenther $<$ http://www.lavras.mg.gov.br/?page_id=121>.

${ }^{8}$ GURI - Projeto idealizado pelo governo do Estado de São Paulo para o ensino musical geral.

${ }^{9}$ Conservatório Dramático Carlos de Campos de Tatuí <http://www.conservatoriodetatui.org.br/>.

${ }^{10}$ Escola Municipal de Ourinhos <http://escolamunicipaldemusicaourinhos.blogspot.com.br/>.

\section{Correspondência}

Miguel Claudio Moriel Chacon - Universidade Estadual Paulista Júlio de Mesquita Filho, Faculdade de Filosofia e Ciências - Campus de Marília, Departamento de Educação Especial. CEP: 17525900 - Marília, São Paulo, Brasil.

E-mail: fabianapsicopedagogiamusical@gmail.com - miguelchacon@unesp.marilia.com

Recebido em 30 de julho de 2015

Aprovado em 20 de novembro de 2015

Revista Educação Especial | v. 30 | n. 57 | p. 83-102 | jan./abr. 2017 